\title{
MOMENTUM, HEAT AND MASS TRANSFER IN LOGARITHMIC SPIRAL FLOWS OF INCOMPRESSIBLE VISCOUS FLUIDS*
}

\author{
WEN-JEI YANG \\ Department of Mechanical Engineering, University of Michigan, Ann Arbor, Michigan
}

(Received 19 September 1963 and in revised form 5 February 1964)

\begin{abstract}
This paper presents a theoretical investigation of the transfer of momentum, heat and mass in incompressible viscous flow through a logarithmic spiral channel. The velocity, temperature and concentration profiles are calculated by the direct integration of the ordinary differential equations obtained from the governing transfer equations by means of the similarity transformation technique. Numerical results are obtained for the shear stress and the rates of heat and mass transfer at the channel walls. As a special case, the analytical solution in a closed form is given for circular Couette flow. Results may be applied to the vapor-heated Rosenblad-type spiral plate heat exchanger and the cooling of bearings.
\end{abstract}

\section{NOMENCLATURE}

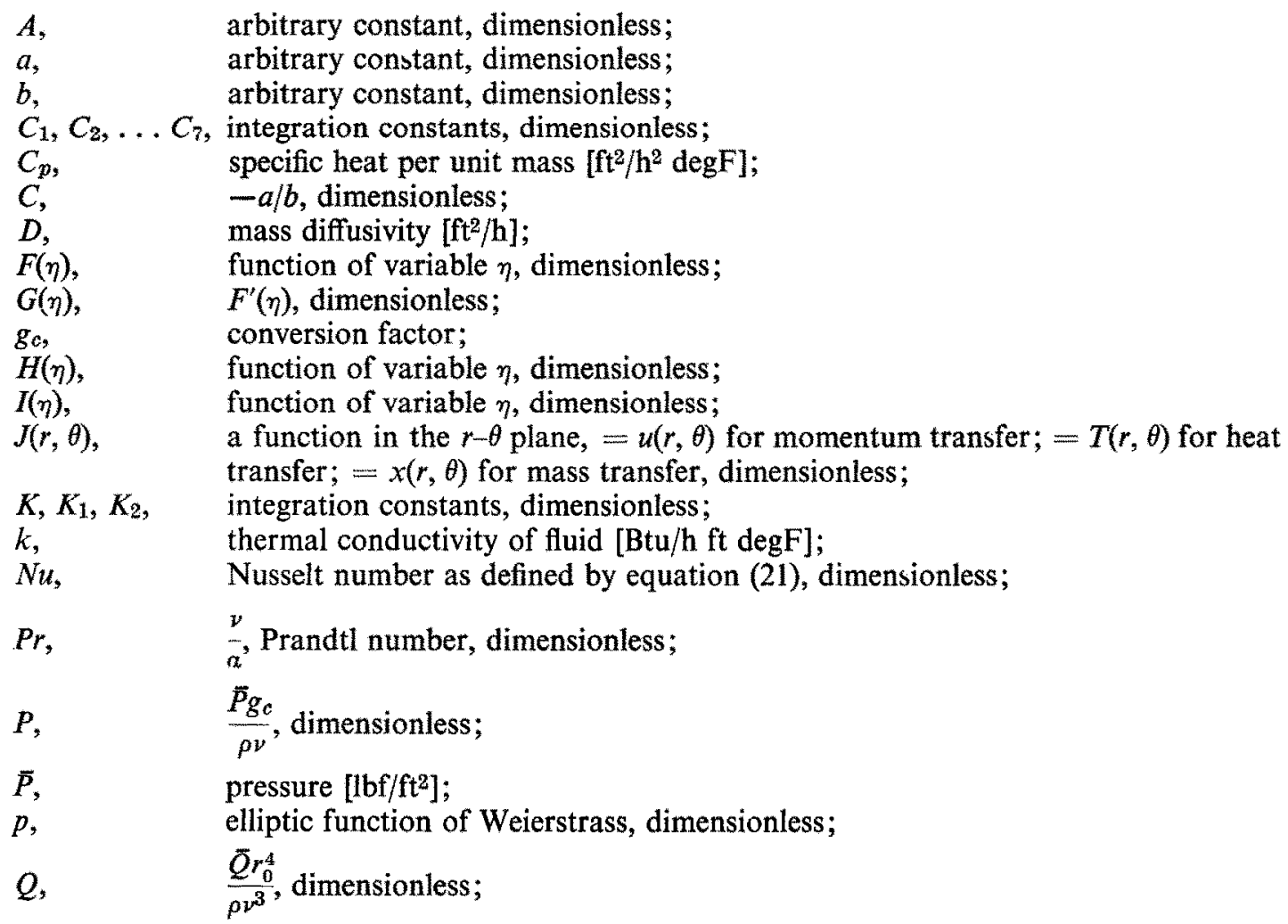

*A publication from the Heat Transfer and Thermodynamics Laboratory, Department of Mechanical Engineering, University of Michigan. The work reported was supported by the Faculty Research Fund of the Horace H. Rackham School of Graduate Studies, University of Michigan. 
$\bar{Q}, \quad \quad$ volumetric rate of internal heat generation in fluid $\left[\mathrm{lbm} / \mathrm{h}^{3} \mathrm{ft}\right]$;

$q$,

$R$

$\bar{R}$

$\operatorname{Re}$,

$r$,

$\bar{r}$

$r_{0}$

Sc,

$S h$,

$T$,

$T_{W}$

$\bar{T}$

$\bar{T}_{W}$,

$U$,

$u$,

$u_{\mathrm{av}}$,

$\bar{u}$,

$W$,

$\bar{W}$,

$x$,

$\bar{x}$

$x_{W}$,

$a$,

$\beta_{1}$

$\beta_{2}$,

$\beta_{3}$, heat flux $\left[\mathrm{Btu} / \mathrm{h} \mathrm{ft}^{2}\right]$;

$\frac{\bar{R} r_{0}^{2}}{x_{0}{ }^{2}}$, dimensionless;

molar rate of production of species $A$ in fluid [mols $/ \mathrm{h} \mathrm{ft}^{3}$ );

Reynolds number as defined by equation (15), dimensionless;

$\frac{\bar{r}}{r_{0}}$, radial distance in polar co-ordinate, dimensionless, $r_{1}$ is $r$ at $\eta_{1}$ and $r_{2}$ is $r$ at $\eta_{2}$ for circular Couette flow case;

radial distance in polar co-ordinate [ft];

characteristic length $[\mathrm{ft}]$;

${ }_{\bar{D}}^{\nu}$ Schmidt number, dimensionless;

Sherwood number as defined by equation (26), dimensionless;

$\frac{C_{p} \bar{T} r_{0}^{2}}{\nu^{2}}$, dimensionless;

$\frac{C_{p} \bar{T}_{W} r_{0}^{2}}{\nu^{2}}$, dimensionless, $T_{W 1}=T_{W}\left(\eta_{1}\right)$ and $T_{W 2}=T_{W}(\eta)$ for circular Couette flow case;

fluid temperature $\left[{ }^{\circ} \mathrm{F}\right]$;

wall temperature $\left[{ }^{\circ} \mathrm{F}\right]$;

$\left[\left(\frac{\partial \psi}{\partial r}\right)^{2}+\left(\frac{1}{r} \frac{\partial \psi}{\partial \theta}\right)^{2}\right]^{1 / 2}$, dimensionless;

$\frac{\bar{u} r_{0}}{\nu}$, dimensionless;

average fluid velocity, dimensionless;

fluid velocity $[\mathrm{ft} / \mathrm{h}]$;

$\frac{\bar{W}}{\nu}$, dimensionless;

volumetric rate of fluid in channel $\left[\mathrm{ft}^{3} / \mathrm{h} \mathrm{ft}\right]$;

$\frac{x}{x_{0}}$, dimensionless;

concentration of species $A\left[\mathrm{mols} / \mathrm{ft}^{3}\right]$;

reference concentration (or concentration at logarithmic spiral channels) of species $A\left[\mathrm{mols} / \mathrm{ft}^{3}\right], x_{W 1}=x_{W}\left(\eta_{1}\right)$ and $x_{W 2}=x_{W}\left(\eta_{2}\right)$ for circular Couette flow case; thermal diffusivity $\left[\mathrm{ft}^{2} / \mathrm{h}\right]$;

$\frac{r_{2} u_{2}-r_{1} u_{1}}{r_{2}^{2}-r_{1}^{2}}$, dimensionless;

$\frac{r_{1} r_{2}\left(r_{2} r_{1}-r_{1} u_{1}\right)}{r_{2}^{2}-r_{1}^{2}}$, dimensionless;

$\frac{1}{\exp \left(-a \eta_{2}\right)-\exp \left(-a \eta_{1}\right)}\left\{\left[\eta_{1} \exp \left(-a \eta_{1}\right)-\eta_{2} \exp \left(-a \eta_{2}\right)\right] \beta_{4}\right.$

$\left.+T_{W 2} \exp \left(-a \eta_{2}\right)-T_{W 1} \exp \left(-a \eta_{1}\right)\right\}$, dimensionless; 


$$
\begin{aligned}
& \beta_{4}, \quad \frac{1}{\eta_{1}-\eta_{2}}\left\{\beta_{2}^{2} \operatorname{Pr}\left[\exp \left(a_{1}\right)-\exp \left(a_{2}\right)\right]+T_{W 1}-T_{W 2}\right\}, \text { dimensionless; } \\
& \beta_{5}, \quad \frac{1}{\exp \left(a \eta_{2}\right)-\exp \left(a \eta_{1}\right)}\left\{\left[\eta_{1} \exp \left(a \eta_{1}\right)-\eta_{2} \exp \left(a \eta_{2}\right)\right] \beta_{6}\right. \\
& \left.+x_{W_{2}} \exp \left(a \eta_{2}\right)-x_{w_{1}} \exp \left(a \eta_{1}\right)\right\} \text {, dimensionless; } \\
& \beta_{6} \\
& \begin{aligned}
\frac{1}{4\left(\eta_{1}-\eta_{2}\right)}\left(\left[4 x_{W_{1}} \exp \left(a \eta_{1}\right)\right.\right. & \left.+S_{c} R\right]\left[\exp \left(-a \eta_{1}\right)-\exp \left(-a \eta_{2}\right)\right] \\
& \left.+4\left\{x_{W 1} \exp \left[a\left(\eta_{1}-\eta_{2}\right)\right]-x_{W_{2}}\right\}\right), \text { dimensionless. }
\end{aligned}
\end{aligned}
$$

Greek symbols

$\eta$

$\theta$

$v$,

$p$,

$\phi$

$\chi$

$\psi(r, \theta)$,

$\bar{\psi}(r, \theta)$

Superscripts

,", ",,$"$, variable, dimensionless;

angle in polar co-ordinate, radians;

kinematic viscosity $\left[\mathrm{ft}^{2} / \mathrm{h}\right]$;

fluid density [ $\left[\mathrm{bm} / \mathrm{ft}^{3}\right]$;

angle formed by $\eta$ and the positive $r$-axis, dimensionless;

variable, dimensionless;

$\frac{\psi}{\nu}$, dimensionless;

Stokes stream function $\left[\mathrm{ft}^{2} / \mathrm{h}\right]$.

\section{Subscripts \\ $r$, \\ $\theta$ \\ av, \\ ( )}

first. second, third, and fourth derivatives with respect to $\eta$

radial dircetion;

angular direction;

average;

function evaluated at a constant $\eta$.

\section{INTRODUCTION}

THE CLASSICAL problem of the "spiral flows" of incompressible viscous fluids was first studied by Jeffery [1] and Hamel [2]. Hamel considered a two-dimensional motion, known as "Hamel's flows" in which the streamlines coincide with an isometric family of curves. These curves were proved to be a set of logarithmic spirals $[2,3]$. By employing the Stokes stream function defined as a function of the logarithmic spiral, he was able to reduce the Navier-Stokes cquation of motion for an incompressible plane flow to an ordinary differential equation. The general integration of this differential equation was performed by Olsson and Faxén [4]. In their solution the technique for the numerical evaluation of the velocity profile involves a graphical construction and requires considerable effort.
Oseen [5] has generalized Hamel's considera* tions by defining the stream function in a more general way. This flow is classified as "Oseen's flow". Further discussions of the spiral flows have been given by Rosenblatt [6] and Birchoff [7]. Recently equations of heat and mass diffusion in spiral flows have been reduced to ordinary differential equations through the use of the similarity transformation technique [8]. General exact solutions of these differential equations are obtained [9].

This paper presents the momentum, heat and mass transfer in incompressible flow through a logarithmic spiral channel. The partial differential equations governing fluid motion, heat transfer and mass transfer are reduced to the ordinary differential equations by the similarity transformation technique. The functions which 
determined the velocity, temperature and concentration profiles are evaluated. Numerical results are obtained for the shear stress and the rates of heat and mass transfer at the channel walls. As a special case, the analytical solution in a closed form is given for circular Couette flow. Results may be applied to the vaporheated Rosenblad-type spiral plate heat exchanger and the cooling of bearings.

\section{ANALYSIS}

The physical system analysed is shown in
Fig. 1. It consists of an incompressible fluid flowing steadily through a logarithmic spiral channel formed by curves $B$ and $C$ which may be expressed in the form

$$
\eta=-\begin{gathered}
2 \\
a^{2}+b^{2}(a \ln r+b \theta) .
\end{gathered}
$$

The channel walls $B$ and $C$ are assumed at uniform temperature $T_{W}$ for heat-transfer analysis and at uniform concentration $x_{W}$ for mass-transfer analysis.

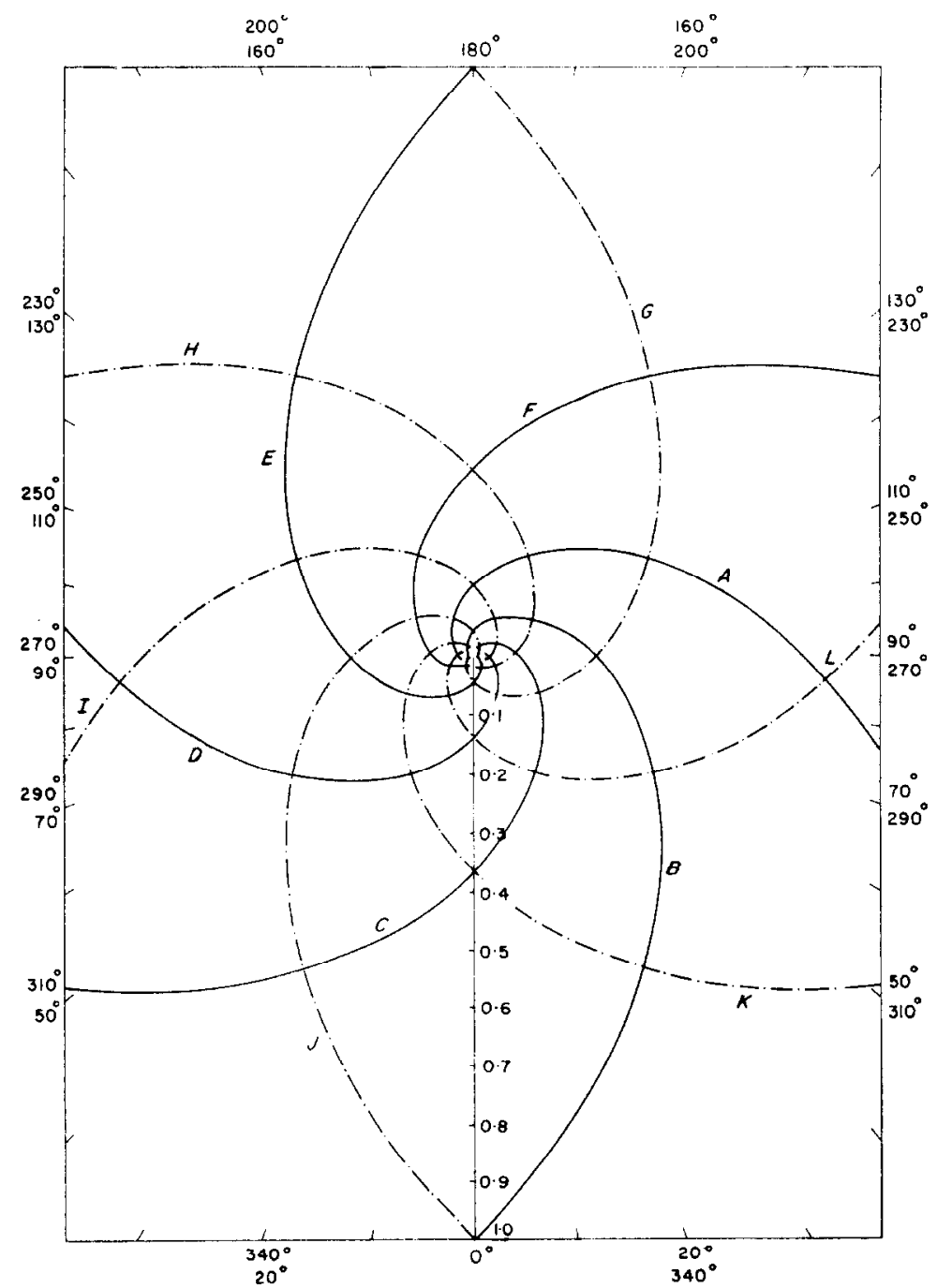

FIG. 1. A family of logarithmic spirals $\eta$ and $\chi$ for $a= \pm 1$ and $b= \pm 1$. 


\section{Momentum transfer}

If the Stokes stream function is defined as

$$
\psi(r, \theta)=F(\eta)
$$

such that

$$
u_{r}=-\frac{1}{r} \cdot \frac{\partial \psi}{\partial \theta}
$$

and

$$
u_{\theta}=\frac{\partial \psi}{\partial r}
$$

express the velocity components in the radial and circular directions, then the NavierStokes equation for incompressible plane flows in polar co-ordinates

$$
\nabla^{4} \psi==\frac{1}{r} \cdot \frac{\partial\left(\nabla^{2} \psi, \psi\right)}{\partial(\theta, r)}
$$

may be reduced to the ordinary differential equation

$$
F^{\prime \prime \prime}+2 a F^{\prime \prime \prime}+\left(a^{2}+b^{2}\right) F^{\prime \prime}+b F^{\prime} F^{\prime \prime}=0 .
$$

Through the substitution of $G=F^{\prime}$ and then integrating once, equation (3) becomes

$$
G^{\prime \prime}+2 a G^{\prime}+\left(a^{2}+b^{2}\right) G+\frac{b G^{2}}{2}=K
$$

where $K$ is an integration constant. The general integration of equation (4) is performed by Olssen and Faxén [4] for the case of

$$
K=\frac{1}{2 b}\left[\left(a^{2}+b^{2}\right)^{2}-\frac{576}{625} a^{4}\right] .
$$

The solution is given as

$$
\begin{aligned}
& G=\frac{1}{b}\left[12\left(\frac{2 a}{5}\right)^{2} \exp [-(4 / 5) a \eta]\right. \\
& \left.p\left\{\exp [-(2 / 5) a \eta]+K_{1}, 0, K_{2}\right\}+\left(\frac{a}{5}\right)^{2}+b^{2}\right]
\end{aligned}
$$

where $p$ is the elliptic function of Weierstrass. The velocity profile is

$$
u=\frac{2 G}{r\left(a^{2}+b^{2}\right)^{1 / 2}} .
$$

The no-slippage condition on the channel wall requires that the integration constants $K_{1}$ and $K_{2}$ in equation (5) must satisfy the boundary conditions for zero velocity: $G\left(\eta_{1}\right)=0$ and $G\left(\eta_{2}\right)=0$, where $\eta_{1}$ and $\eta_{2}$ are the two walls of the channel. Due to difficulty in determining $K_{1}$ and $K_{2}$, a technique involving graphical construction was applied for the numerical evaluation of velocity profiles [4]. This requires considerable effort. Fortunately the advent of the computing machine permits one to obtain the function $G(\eta)$ by numerical integration.

The shear stress is obtained as follows:

Consider a function $J(r, \theta)$, which represents the velocity $u(r, \theta)$ for momentum transfer, the temperature $T(r, \theta)$ for heat transfer and the concentration $x(r, \theta)$ for mass transfer, and its rate of change in the direction of

$$
\chi=\frac{2}{a^{2}+b^{2}}(b \ln r-a \theta)
$$

which is orthogonal to $\eta$. If $\eta$ makes an angle $\phi$ with the positive $r$-axis, then the directional derivative of $J$ in the direction of $x$ may be written as

$$
\frac{\partial J}{\partial \chi}=-\frac{\partial J}{\partial r} \sin \phi+\frac{1}{r} \frac{\partial J}{\partial \theta} \cos \phi
$$

where the direction sine and cosine are

$$
\cos \phi=\frac{J r}{J}=\frac{b}{\sqrt{\left(a^{2}+b^{2}\right)}}
$$

and

$$
\sin \phi=\frac{J_{\theta}}{J}=-\frac{a}{\sqrt{ }\left(a^{2}+b^{2}\right)}
$$

respectively. Therefore the shear stress, defined as $\tau=-(\partial u / \partial \chi)$, may be expressed as

$$
\tau(\eta)=\frac{2\left(2 G^{\prime}+a G\right)}{r^{2}\left(a^{2}+b^{2}\right)}
$$

At the spiral channel walls $\eta_{1}$ and $\eta_{2}$, where $G\left(\eta_{1}\right)=0$ and $G\left(\eta_{2}\right)=0$, the wall shear stresses are

$$
\tau\left(\eta_{1}\right)=\frac{4 G^{\prime}\left(\eta_{1}\right)}{a^{2}+b^{2}} \exp \left(a \eta_{1}-b \chi\right)
$$


and

$$
\tau\left(\eta_{2}\right)=\frac{4 G^{\prime}\left(\eta_{2}\right)}{a^{2}+b^{2}} \exp \left(a \eta_{2}-b_{X}\right)
$$

respectively.

Pressure is obtained from reference 6 as

$$
\begin{aligned}
& \mathrm{d} P=-\frac{1}{2} \mathrm{~d} U^{2}+\frac{4 \exp (a \eta-b \chi)}{a^{2}+b^{2}} \\
& \quad\left[G \cdot G^{\prime} \cdot \mathrm{d} \eta+G^{\prime \prime} \mathrm{d} \chi+G^{\prime}(a \mathrm{~d} \chi+b \mathrm{~d} \eta)\right] .
\end{aligned}
$$

The integration of equation (12) yields

$$
P=\frac{4}{\left(a^{2}+b^{2}\right) b r^{2}}\left[\left(a^{2}+b^{2}\right) G+a G^{\prime}-K\right] \text {. ( }
$$

The average fluid velocity is defined as

$$
u_{\mathrm{av}}=\frac{1}{\eta_{2}-\eta_{1}} \int_{\eta_{\mathrm{i}}}^{\eta_{2}} u \mathrm{~d} \eta_{2}
$$

since the volumetric rate of fluid flow in the channel is

$$
\begin{aligned}
& W=\int_{\eta_{1}}^{\eta_{z}} u d \eta=\frac{2}{\sqrt{\left(a^{2}+b^{2}\right)}} \\
& \int_{\eta_{1}}^{\eta_{z}} G(\eta) \exp [(a \eta-b \chi) / 2] \cdot \mathrm{d} \eta
\end{aligned}
$$

and the cross-sectional area of the channel is $\left(\eta_{2}-\eta_{1}\right)$ per unit thickness. The hydraulic diameter of two logarithmic spiral planes located a distance $\left(\eta_{2}-\eta_{1}\right)$ apart in the orthogonal (or $x$ ) direction is $2\left(\eta_{2}-\eta_{1}\right)$. Using this in the definition of the Reynolds number results in

$$
R e=2 u_{\mathrm{av}}\left(\eta_{2}-\eta_{\mathrm{I}}\right)=2 \int_{\eta_{\mathrm{z}}}^{\eta_{3}} u \mathrm{~d} \eta
$$

It is interesting to compare this result with the potential flow of the classical theory. By this theory the potential flow must satisfy $\Delta \psi=0$. This results in

$$
F(\eta)=C_{1} \eta+C_{2}
$$

The velocity profile for the case is

$$
u=\frac{2 C_{1}}{r \sqrt{\left(a^{2}+b^{2}\right)}}
$$

The integration constant $C_{1}$ in equation (16) has to be determined by the volumetric rate of fluid flow in the spiral channel. By equating the volumetric rate in viscous flow as expressed by equation (14) to that in potential flow which is

$$
W \cdots \frac{2 C_{1}}{\sqrt{ }\left(a^{2}+b^{2}\right)} \int_{\eta_{n}}^{\eta_{z}} \exp [(a \eta-b \chi) / 2] \cdot \mathrm{d} \eta
$$

one obtains

$$
C_{1}=\frac{\int_{\eta_{1}}^{\eta_{k}} G(\eta) \exp [(a \eta-b x) / 2] \cdot \mathrm{d} \eta}{\int_{\eta_{1}}^{\eta_{2}} \exp \left[\left(a \eta-b_{\chi}\right) / 2\right] \cdot \mathrm{d} \eta} .
$$

Equation (17) reveals that the velocity is simply inversely proportional to the distance from the inlet. This indicates that the potential fiow velocity has its maximum at the inner channel wall.

\section{Heat transfer}

Energy equation including viscous heating terms may be expressed as

$$
\begin{gathered}
u r \frac{\partial T}{\partial r}+\frac{u_{\theta} \partial T}{r} \frac{1}{\partial \theta}=\frac{1}{\operatorname{Pr}}\left[\frac{1}{r \partial r}\left(\frac{\partial T}{\partial r}\right)\right. \\
\left.+\frac{1}{r^{2}} \cdot \frac{\partial^{2} T}{\partial \theta^{2}}\right]+2\left[\left(\begin{array}{c}
\partial u r \\
\partial r
\end{array}\right)^{2}+\frac{1}{r^{2}}\left(\frac{\partial u_{\theta}}{\partial \theta}+u r\right)^{2}\right] \\
+\left[\frac{1}{r} \partial \theta+r \frac{\partial}{\partial \theta}+\left(\begin{array}{c}
u_{t} \\
r
\end{array}\right)\right]^{2}
\end{gathered}
$$

in polar co-ordinates. Through the transformation of

$$
\begin{aligned}
& T(r, \theta)-T_{W}= \\
& \frac{H(\eta)}{r^{2}}\left[\text { or }=\exp \left(a \eta-b_{\chi}\right) \cdot H(\eta)\right]
\end{aligned}
$$

equation (18) may be reduced to the ordinary differential equation

$$
\begin{aligned}
& H^{\prime \prime}+2 a H^{\prime}+\left(a^{2}+b^{2}+b \operatorname{Pr} G\right) H \\
& \quad+4 \operatorname{Pr}\left(\frac{G^{2}}{a^{2}+b^{2}}+G^{2}+\frac{2 a G G^{\prime}}{a^{2}+b^{2}}\right)=0 .
\end{aligned}
$$

If the spiral channel walls $\eta_{1}$ and $\eta_{2}$ are at uniform temperature $T_{W}$, then the function 
$H(\eta)$ in equation (20) has to satisfy the boundary conditions

$$
H\left(\eta_{1}\right)=0 \text { and } H\left(\eta_{2}\right)=0 .
$$

The temperature gradient in the $x$ direction may be obtained from equation (8) as

$$
\frac{\partial T}{\partial \chi}=-\frac{2}{r^{3} \sqrt{ }\left(a^{2}+b^{2}\right)}\left(H^{\prime}+a H\right) .
$$

Since along a constant $\chi$ line, the average temperature difference between a channel wall and the fluid is

$$
\begin{aligned}
& \left(T-T_{W}\right)_{\mathrm{av}}= \\
& \frac{1}{\eta_{2}-\eta_{1}} \int_{\eta_{1}}^{\eta_{0}} H(\eta) \exp (a \eta-b \chi) \mathrm{d} \eta
\end{aligned}
$$

and the characteristic length is $2\left(\eta_{2}-\eta_{1}\right)$, therefore, one can define the Nusselt number as

$$
\begin{aligned}
& N u=\frac{2 q\left(\eta_{2}-\eta_{1}\right)}{k\left(T-T_{W}\right)_{\mathrm{av}}} \\
&=\frac{2(\partial T / \partial \chi)_{\eta}\left(\eta_{2}-\eta_{1}\right)}{\left(T-T_{W}\right)_{\mathrm{av}}} .
\end{aligned}
$$

Then the Nusselt numbers at the spiral channel walls $\eta_{1}$ and $\eta_{2}$ be expressed as

$$
N u\left(\eta_{1}\right)=\frac{4\left(\eta_{2}-\eta_{1}\right)^{2} H^{\prime}\left(\eta_{1}\right) \exp \left[3 / 2\left(a \eta_{1}-b_{\chi}\right)\right]}{\sqrt{ }\left(a^{2}+b^{2}\right) \int_{\eta_{1}}^{\eta_{2}} H(\eta) \exp (a \eta-b \chi) \cdot \mathrm{d} \eta}
$$

and

$$
N u\left(\eta_{2}\right)=\frac{4\left(\eta_{2}-\eta_{1}\right)^{2} H^{\prime}\left(\eta_{2}\right) \exp \left[3 / 2\left(a \eta_{2}-b \chi\right)\right]}{\sqrt{ }\left(a^{2}+b^{2}\right) \int_{\eta_{1}}^{\eta_{2}} H(\eta) \exp (a \eta-b \chi) \mathrm{d} \eta}
$$

respectively.

\section{Mass transfer}

In case of mass transfer, the mass equation in the polar co-ordinate for a flowing fluid with internal mass generation:

$$
\begin{aligned}
& u r \frac{\partial x}{\partial r}+\frac{u_{\theta}}{r} \frac{\partial x}{\partial \theta} \\
& =\frac{1}{S c}\left[\frac{1}{r} \frac{\partial}{\partial r}\left(r \frac{\partial x}{\partial r}\right)+\frac{1}{r^{2}} \frac{\partial^{2} x}{\partial \theta^{2}}\right]+R
\end{aligned}
$$

may be reduced to the ordinary differential equation

$$
\begin{aligned}
& I^{\prime \prime}-2 a I^{\prime}+\left(a^{2}+b^{2}-b S c G\right) I \\
& +\stackrel{a^{2}+b^{2}}{4} \text { Sc } R-0
\end{aligned}
$$

by the transformation

$$
\begin{aligned}
x(r, \theta)-x_{W} & =r^{2} I(\eta) \\
& {[\mathrm{or}=\exp (b x-a \eta) \cdot I(\eta)] . }
\end{aligned}
$$

The boundary conditions to be imposed on the spiral channel walls $\eta_{1}$ and $\eta_{2}$ at uniform concentration $X_{W}$ are

$$
I\left(\eta_{1}\right)=0 \quad \text { and } \quad I\left(\eta_{2}\right)=0 .
$$

Along a constant $\chi$ line, one has

$$
\frac{\partial x}{\partial \chi}=\frac{2 r}{\sqrt{ }\left(a^{2}+b^{2}\right)}\left(a I-I^{\prime}\right)
$$

as the concentration gradient,

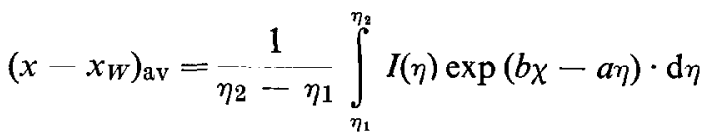

as the definition of the average concentration difference, and $2\left(\eta_{2}-\eta_{1}\right)$ as the characteristic length. Using these expressions in the definition of the Sherwood number results in

$$
S h(\eta)=\frac{2(\partial x / \partial x) /\left(\eta_{2}-\eta_{1}\right)}{\left(x-x_{W}\right)_{\mathrm{av}}} .
$$

Then at the spiral channel walls $\eta_{1}$ and $\eta_{2}$, the Sherwood numbers may be written as

$$
S h\left(\eta_{1}\right)=\frac{4\left(\eta_{2}-\eta_{1}\right)^{2} I^{\prime}\left(\eta_{1}\right) \exp \left[1 / 2\left(b \chi-\eta_{1}\right)\right]}{\sqrt{ }\left(a^{2}+b^{2}\right) \int_{\eta_{1}}^{\eta_{2}} I(\eta) \exp (b \chi-a \eta) \cdot \mathrm{d} \eta}
$$

and

$$
S h\left(\eta_{2}\right)=\frac{4\left(\eta_{2}-\eta_{1}\right)^{2} I^{\prime}\left(\eta_{2}\right) \exp \left[1 / 2\left(b_{\chi}-a \eta_{2}\right)\right]}{\sqrt{ }\left(a^{2}+b^{2}\right) \int_{\eta_{1}}^{\eta_{2}} I(\eta) \exp \left(b_{\chi}-a \eta\right) \cdot \mathrm{d} \eta}
$$

respectively.

By applying the analogy between heat and mass transfer, results for heat transfer due to 
the internal heat generation in a fluid with negligible viscous heating may be obtained from equations (24) through (28) by replacing $X$ for $T, \chi_{W}$ for $T_{W}, S c$ for $P r, R$ for $Q$ and $S h$ for $\mathrm{Nu}$.

\section{SPECIAL CASES}

Two limiting special cases which have important applications are to be analysed. They are the radial flow in channels $(a=0)$ and the circular Couette flow $(b=0)$.

\section{(i) Radial flow in channels}

Rosenblatt [6] has obtained the exact solution for the velocity distribution in radial flow, $a=0$, as an elliptic function of $\theta$. Considerable effort is required for numerical evaluation of his solution.

Results for heat and mass transfer may be readily obtained from the preceding analysis by merely substituting $a=0$.

\section{(ii) Circular Couette flows}

For the circular Couette flow, $b=0$, equation (4) may be integrated to give

$$
G=\left(c_{3}+c_{4} \eta\right) \exp (-a \eta)+\frac{K}{a^{2}}
$$

Since $\chi$ as expressed by equation (7) is proportional to $\theta$ for this case, the condition of constant pressure in the circular direction has to be be satisfied. This condition which is obtained from equation (12) as $G^{\prime \prime}+a G^{\prime}=0$ reduces equation (4) to the first order differential equation

$$
a G^{\prime}+a^{2} G=K .
$$

If $u_{1}$ and $u_{2}$ are respectively the velocities of two concentric walls with radii $r_{1}$ and $r_{2}$, then equation (29) is integrated to give

$$
G^{\prime}(r)=\frac{a}{2}\left(\beta_{1} r^{2}+\beta_{2}\right)
$$

The velocity profile between the concentric walls may be obtained from equations (6) and (30) as

$$
u=\beta_{1} r+\frac{\beta_{2}}{r} \text {. }
$$

The Reynolds number, shear stress and pressure distribution as respectively defined by equations (15), (9) and (13) become

$$
\begin{aligned}
R e & =\beta_{1}\left(r_{2}^{2}-r_{1}^{2}\right)+2 \beta_{2} \ln \frac{r_{2}}{r_{1}} \\
\tau & =\frac{\beta_{2}}{r^{2}}-\beta_{1} \\
P & =\frac{\beta_{2}^{2} r^{2}}{2}-\frac{\beta_{1}^{2}}{2 r^{2}}+2 \beta_{1} \beta_{2} \ln r .
\end{aligned}
$$

The function $H(\eta)$ for heat transfer, defined as $r^{2} T(r, \theta)$ for this special case, may be obtained by the integration of equation (20) for $b=0$ :

$$
H(\eta)=\left(c_{5}+c_{6} \eta\right) \exp (-a \eta)-\beta_{2}^{2} \operatorname{Pr} .
$$

Therefore from equation (19), one obtains the temperature profile in the fluid between the two concentric walls maintained at uniform temperatures $T_{W 1}$ and $T_{W 2}$ as

$$
T(\eta)=\beta_{3}+\beta_{4} \eta-\beta_{2}^{2} \operatorname{Pr} \exp (a \eta) .
$$

The Nusselt numbers, as defined by equation (21), are

$$
\begin{aligned}
& N u\left(\eta_{1}\right)=\frac{4\left(\eta_{1}-\eta_{2}\right)\left[a \beta_{2}^{2} \operatorname{Pr} \exp \left(a \eta_{1}\right)-\beta_{4}\right] \exp \left[(a / 2) \eta_{1}\right]}{a\left[\beta_{3}+\frac{\beta_{4}}{2}\left(\eta_{1}+\eta_{2}\right)-\frac{\beta_{2}^{2} \operatorname{Pr}}{\left(\eta_{1}-\eta_{2}\right) a}\left[\exp \left(a \eta_{1}\right)-\exp \left(a \eta_{2}\right)\right]-T_{W 1}\right]} \\
& N u\left(\eta_{2}\right)=\frac{4\left(\eta_{1}-\eta_{2}\right)\left[a \beta_{2}^{2} \operatorname{Pr} \exp \left(a \eta_{2}\right)-\beta_{4}\right] \exp \left[(a / 2) \eta_{2}\right]}{a\left[\beta_{3}+\frac{\beta_{4}}{2}\left(\eta_{1}+\eta_{2}\right)-\frac{\beta_{2}^{2} \operatorname{Pr}}{a\left(\eta_{1}-\eta_{2}\right)}\left[\exp \left(a \eta_{1}\right)-\exp \left(a \eta_{2}\right)\right]-T_{W 2}\right]} .
\end{aligned}
$$

In case of mass transfer, the function $I(\eta)$, defined as $\bar{r}^{2} x(r, \theta)$ for this special case, may be obtained by the integration of equation (24) for $b=0$ :

$$
I=\left(C_{7}+C_{8} \eta\right) \exp (a \eta)-\frac{S c R}{4} \text {. }
$$


Therefore the concentration profile in the fluid between the two concentric walls maintained at uniform concentrations $x_{W 1}$ and $x_{W 2}$ is

$$
x(\eta)=\beta_{5}+\beta_{6} \eta-\frac{S c R}{4} \exp (-a \eta)
$$

The Sherwood numbers, as defined by equation (26), are

$$
\begin{aligned}
& S h\left(\eta_{1}\right)=\frac{2\left(\eta_{2}-\eta_{1}\right)\left(\frac{2 \beta_{6}}{a} \exp (a / 2) \eta_{1}+\frac{S c R}{2} \exp \left[-(a / 2) \eta_{1}\right]\right)}{\beta_{5}+\frac{\beta_{6}}{2}\left(\eta_{1}+\eta_{2}\right)+\begin{array}{c}
S c R \\
4 a
\end{array} \cdot \frac{\exp \left(-a \eta_{1}\right)-\exp \left(-a \eta_{2}\right)}{\eta_{1}-\eta_{2}}-x_{W}\left(\eta_{1}\right)} \\
& S h\left(\eta_{2}\right)=\frac{2\left(\eta_{2}-\eta_{1}\right)\left(\frac{2 \beta_{6}}{a} \exp (a / 2) \eta_{2}+\frac{S c R}{2} \exp \left[-(a / 2) \eta_{2}\right]\right)}{\beta_{5}+\frac{\beta_{6}}{2}\left(\eta_{1}+\eta_{2}\right)+\frac{S c R}{4 a} \cdot \frac{\exp \left(-a \eta_{1}\right)-\exp \left(-a \eta_{2}\right)}{\eta_{1}-\eta_{2}}-x_{W}\left(\eta_{2}\right)} .
\end{aligned}
$$

\section{RESULTS AND DISCUSSIONS}

Depending on the selection of $a$ and $b$, one can construct an infinite number of logarithmic spirals $\eta$ and $\chi$ as expressed by equations (1) and (7) respectively. A family of these spirals is graphically presented in Fig. 1 for $a= \pm 1$ and $b= \pm 1$. An explanation for the combination of this family of orthogonal functions is given in Table 1. In the following discussion, a representative logarithmic spiral channel with two walls at $\eta_{1}=0$ and $\eta_{2}=1.0$ is selected for the study of momentum, heat and mass transfer. The ratio of $a$ and $b$ is varied in order to investigate the effects of the geometrical configuration of the logarithmic spiral channel on the transport phenomena.
The functions $G(\eta), H(\eta)$ and $I(\eta)$ which determine the velocity, temperature and concentration distributions respectively were evaluated by the numerical integration of equations (4), (20) and (24) using an IBM 7090 digital computer. One representative numerical reduction is given in Table 2 for $a=1, b=1$, $K=1.5392, P r=1, S c=1$ and $R=1$. Using these functions the vclocity, temperature and concentration profiles, as expressed by equations (6), (19) and (25) respectively, are evaluated at four different cross sections $\chi=-1,0,1$ and 2 and are presented in Figs. 2, 3 and 4 respectively. The velocity profile in potential flow as expressed by equation (17) is also presented in Fig. 2 for comparison with the viscous flow case.

Table 1. A family of logarithmic spirals $\eta$ and $\chi$ for $a= \pm 1$ and $b= \pm 1$

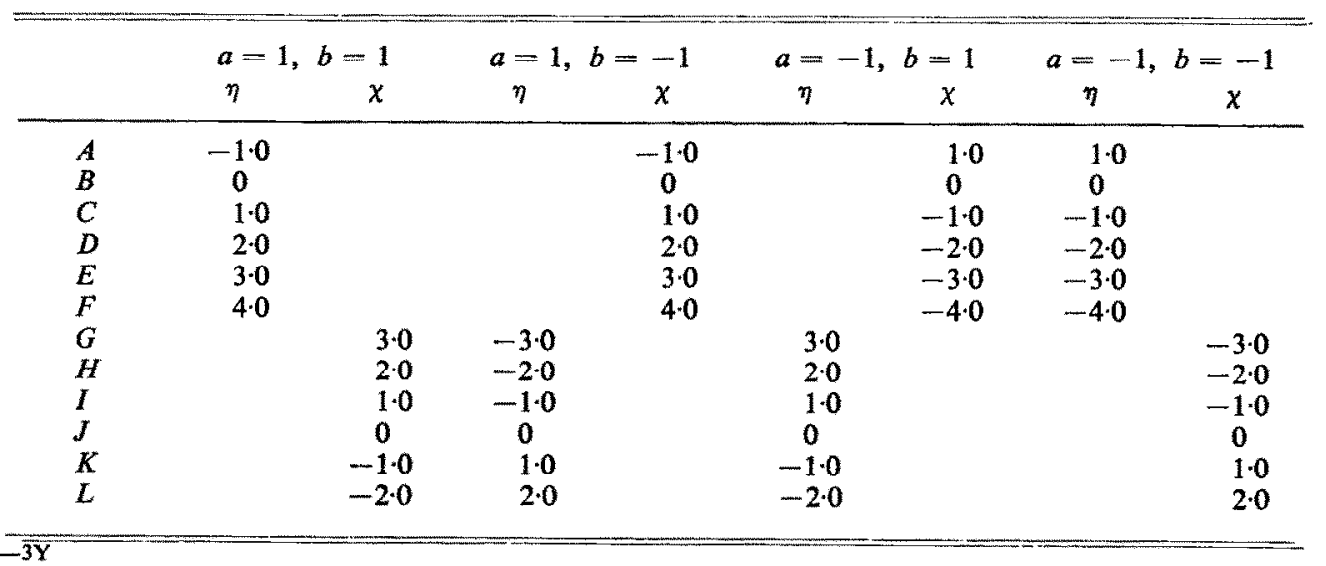


Table 2. $G(\eta), H(\eta)$ and $I(\eta)$ functions for $a=1, b=1, \operatorname{Pr}=1, S c=1, R=1, K=1.539200$

\begin{tabular}{|c|c|c|c|c|c|c|c|c|c|}
\hline$\eta$ & $G(n)$ & $G^{\prime}(n)$ & $G^{\prime}(\eta)$ & $H(\eta)$ & $H^{\prime}(\eta)$ & $H^{\prime \prime}(n)$ & $f(\eta)$ & $l^{\prime}(n)$ & $I^{\prime \prime}(7)$ \\
\hline 0 & 0.00000 & $-1 \cdot 22962$ & 3.97078 & 0.00000 & 0.58142 & $-4 \cdot 1508 t$ & 0.00000 & 0.20377 & 0.09543 \\
\hline 0.1 & -0.11228 & -0.82282 & $3 \cdot 40311$ & 0.04299 & 0.23439 & $-2 \cdot 32431$ & 0.02172 & 0.18969 & $-0 \cdot 16649$ \\
\hline 0.2 & -0.17841 & -0.50817 & $2 \cdot 89644$ & 0.05696 & 0.06302 & $-1 \cdot 23645$ & 0.03972 & $0 \cdot 16905$ & $-0 \cdot 24843$ \\
\hline $0 \cdot 3$ & -0.21554 & -0.24214 & 2.43134 & 0.05843 & -0.02272 & -0.57082 & 0.05523 & 0.13956 & -0.34324 \\
\hline $0-4$ & -0.22832 & -0.02042 & 2.01060 & 0.05407 & -0.05857 & -0.20671 & 0.06730 & 0.09999 & -0.44997 \\
\hline 0.5 & -0.22095 & 0.16144 & 1.63380 & 0.04753 & -0.06961 & -0.05009 & 0.07485 & 0.04919 & -0.56786 \\
\hline 0.6 & $-\ldots \times 19721$ & 0.30773 & 1.29871 & 0.04040 & -0.07271 & -0.02963 & 0.07672 & -0.01393 & -0.69643 \\
\hline 0.7 & $-0 \cdot 16046$ & 0.42248 & 1.00229 & 0.03289 & -0.07859 & -0.09210 & 0.07162 & -0.09043 & -0.83559 \\
\hline 0.8 & -0.11365 & 0.50937 & 0.74129 & 0.02439 & -0.09339 & -0.19820 & 0.05816 & $-0 \cdot 18139$ & -0.98570 \\
\hline 0.9 & -0.05940 & 0.57181 & 0.51261 & 0.01382 & -0.11988 & $-0 \cdot 31918$ & 0.03482 & -0.28794 & $-1 \cdot 14760$ \\
\hline $1 \cdot 0$ & 0.001000 & 0.61288 & 0.31344 & 01000000 & -0.15842 & -0.43435 & 0.00000 & -0.41134 & -1.32269 \\
\hline
\end{tabular}

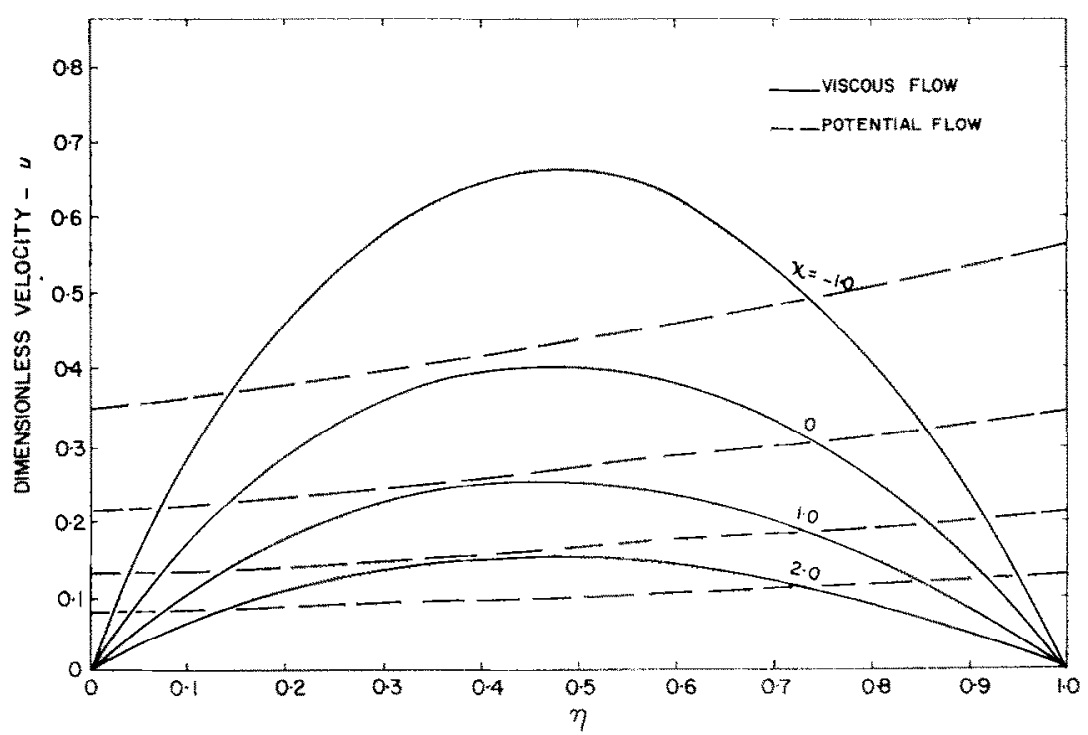

Fig. 2. Velocity distribution in logarithmic spiral channels for $a=1.0, b=1.0$ and $K=1.5392$.

Figure 2 demonstrates that the maximum velocity in viscous flow is shifted to the outer channel wall by centrifugal effects. The velocity for potential flow is simply proportional to the distance from the inlet. Therefore its velocity is greater at the inner channel wall. As illustrated in Figs. 3 and 4, the maximum temperature and concentration are shifted to the outer and inner channel walls respectively. A comparison of velocity distribution at the cross-section $\chi=0$ is presented in Fig. 5 for different values of $a$ and $b$. It shows that for the same value of $K$ the velocity profile decreases in magnitude and the location of the maximum velocity shifts to the outer channel wall as the absolute value of $a / b$ increases. For potential flow, the velocity decreases at the outer channel wall and increases at the inner wall as $|a / b|$ increases. Similarly comparisons are given for the temperature and concentration distributions in Fig. 6 for $P r=S c=R=1.0$. It is observed that as the absolute value of $a / b$ increases, the temperature profile decreases in magnitude with its maximum shifted toward the outer channel wall, and the concentration profile increases in magnitude with its maximum shifted toward the inner wall.

The influence of the Prandtl number on the Nusselt number as defined by equations (22) and (23) is illustrated in Fig. 7. It shows that at low values of the Prandtl number the Nusselt number approaches a fairly constant value. 


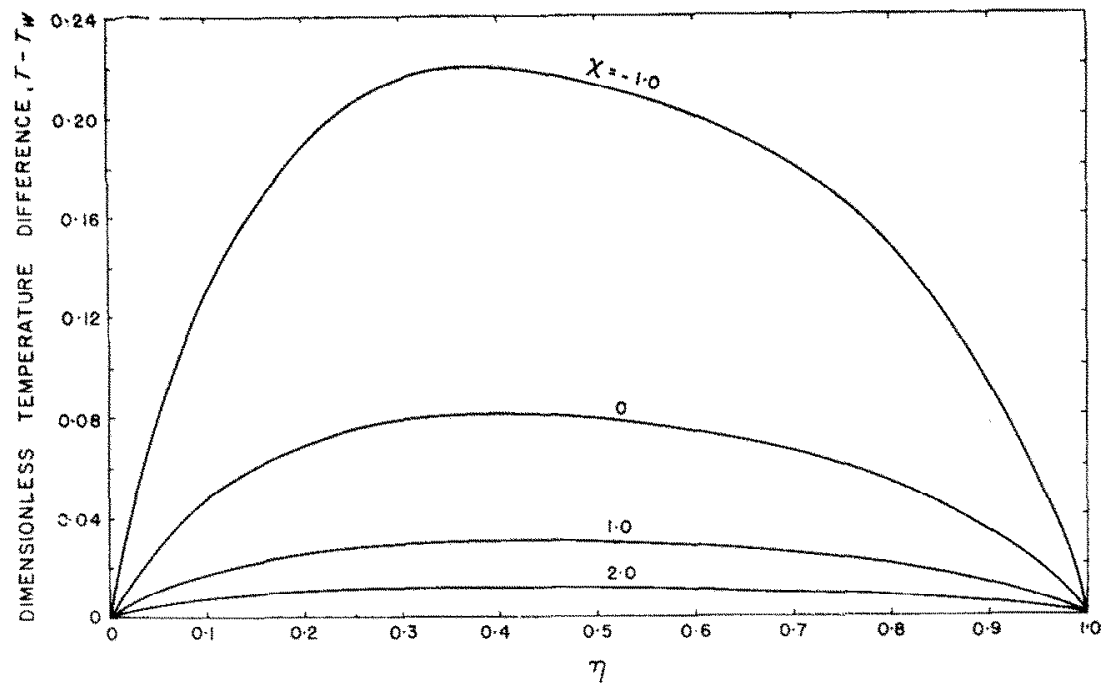

Frg. 3. Temperature distribution in logarithmic spiral channels for $a=1, b=1$ and $P r=1.0$.

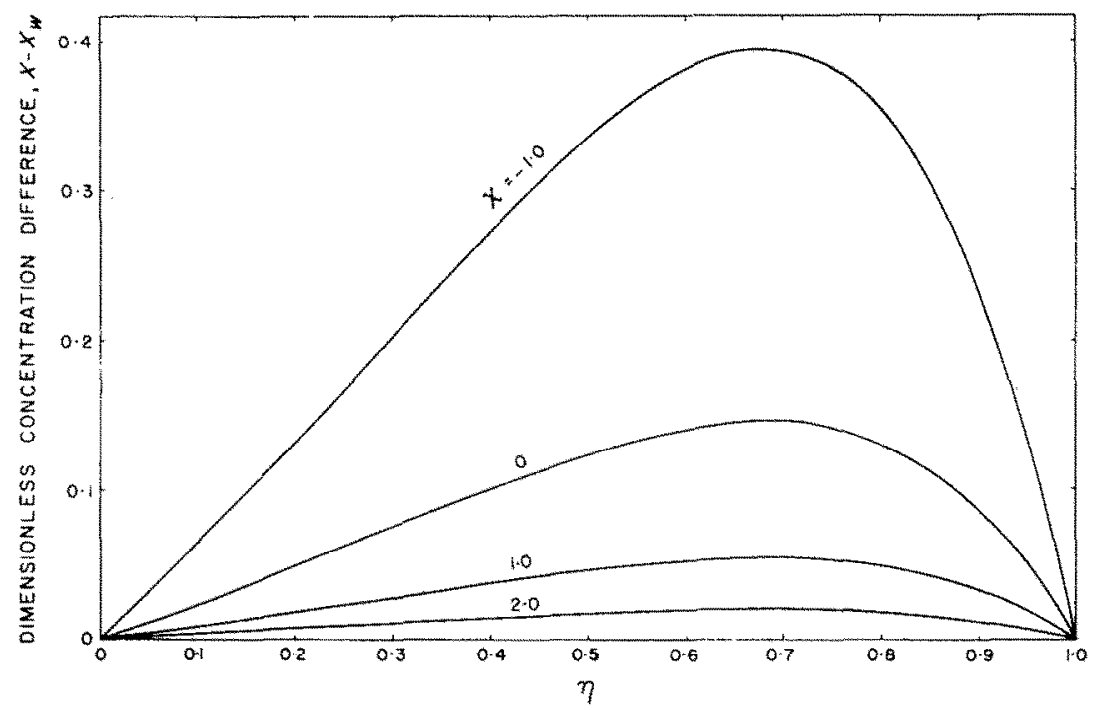

Fig. 4. Concentration distribution in logarithmic spiral channels for $a=1, b=1, S c=1$ and $R=1$.

However, with an increase in the Prandtl number, the Nusselt number follows a rapid increase. Figure 8 demonstrates that the influence of the Schmidt number on the Sherwood number, as defined by equations (27) and (28) is very small at low values of the Schmidt number.

In the range of high Schmidt numbers, the Sherwood number follows a rapid decrease with an increase in the Schmidt number.

It is most interesting to study the relationships between the flow condition and the rates of transport of momentum, heat and mass. Figures 9 and 10 show that the wall shear stresses $\tau\left(\eta_{1}\right)$ and $\tau\left(\eta_{2}\right)$ as defined by equations (10) and (11) vary with the Reynolds number in two distinct manners: First, along the channel with a given inward flow, the wall shear stresses increase along a constant $K$ line with an increase in the Reynolds number by the $\tau \propto R e^{2}$ relationship. This increase in the Reynolds number is related 


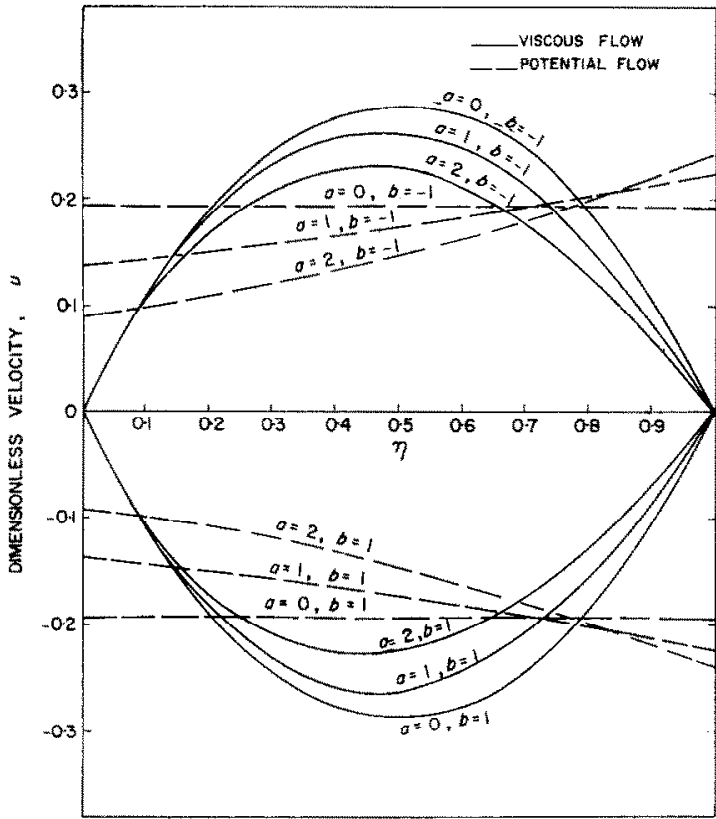

FIG. 5. Comparison of velocity distribution in logarithmic spiral channels of different $a$ and $b_{2}$ at

$$
x=0 \text { for } K=1.0 \text {. }
$$

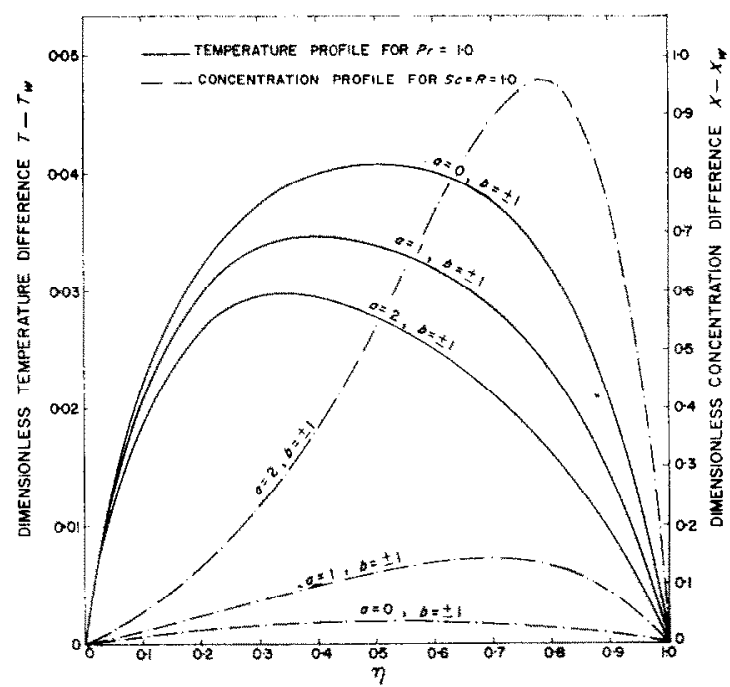

Fig. 6. Comparison of temperature and concentration distribution in logarithmic spiral channels of different $a$ and $b$, at $\chi=0$ for $K=1 \cdot 0$.

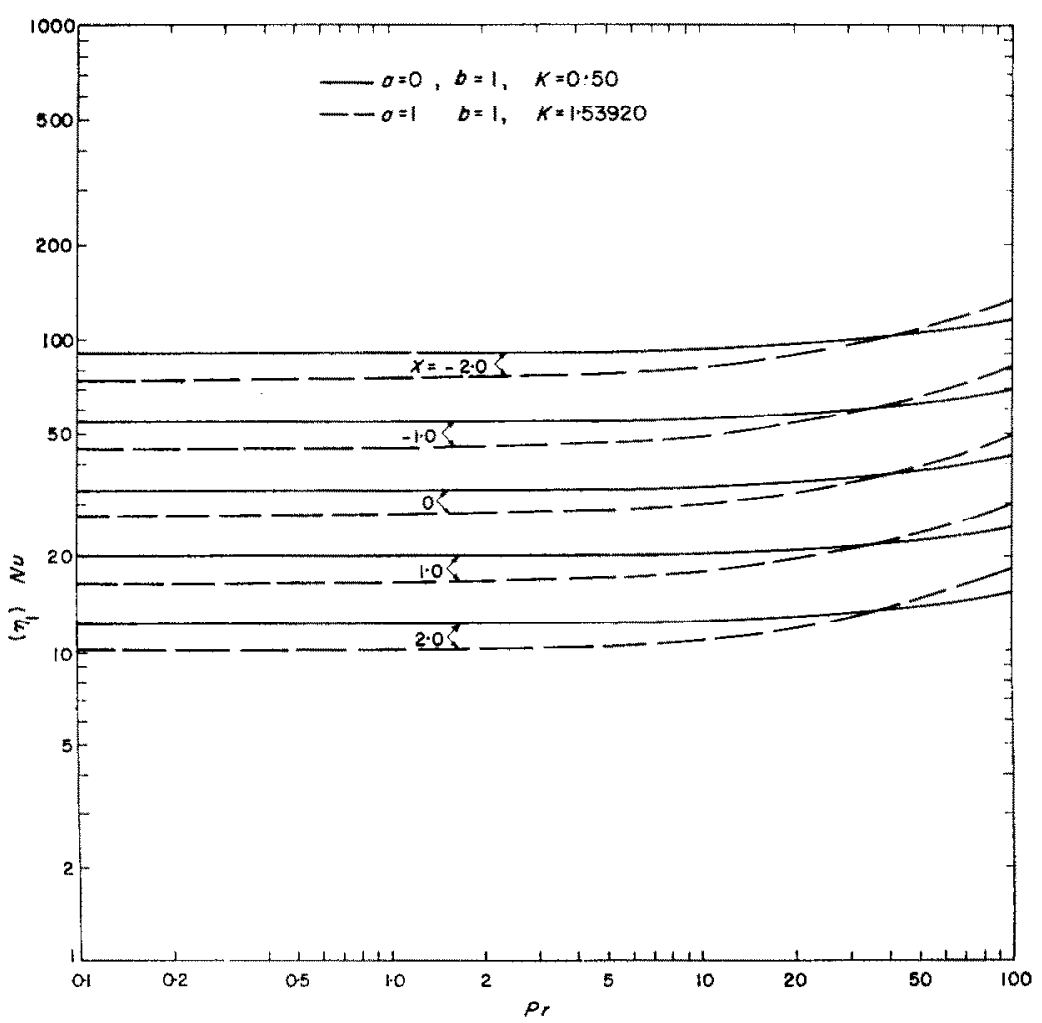

Fic. 7. Effect of $\operatorname{Pr}$ on $\mathrm{Nu}$. 


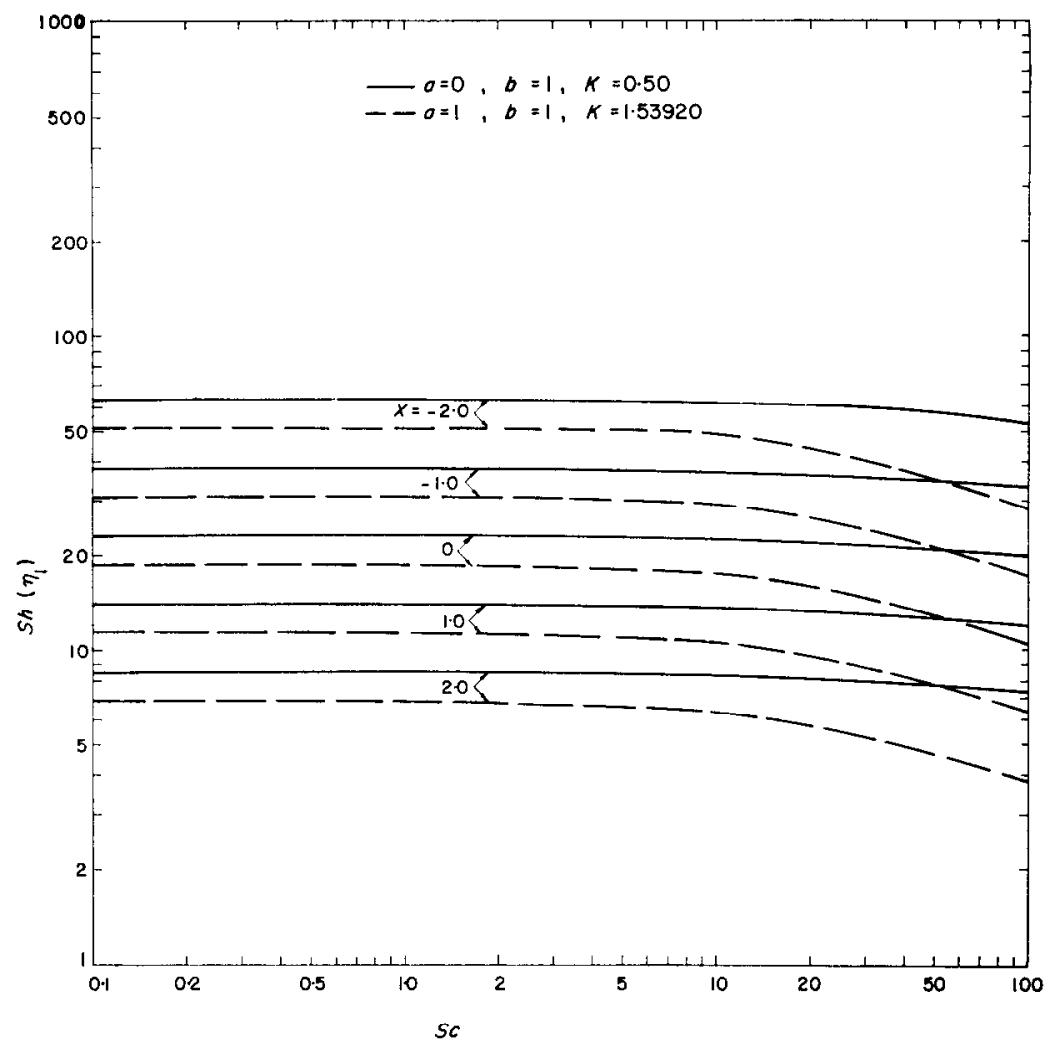

Fig. 8. Effect of $S c$ on $S h$ for $R=0 \cdot 1$.

to the variation of the cross-sectional area along the channel. Second, if the change in the Reynolds number is due to the change of flow rate in the channel then the wall shear stresses increase along a constant $\chi$ line by the $\tau \propto R e$ relationship. The shear stress at the inner wall then increases more rapidly above a certain value of the Reynolds number. Only two representative cases, for $a=0, b=1$ corresponding to the radial channel flow case and $a=1, b=1$ corresponding to the flow in the channel as illustrated in Fig. 1, are included here as Figs. 9 and 10 . However, an extensive study on different sets of $a$ and $b$ (which is not presented here in the interest of brevity) reveals that as the absolute value of $a / b$ increases, the wall shear stresses decrease for a given $\chi$ and $R e$ and their difference becomes more distinct. It is easy to realize that the forementioned phenomena are merely due to the difference in the geometrical configuration of the spiral channels.
The characteristics of dual variation with the Reynolds number is also observed in the rates of heat and mass transfer. Figures 11 and 12 illustrate the relationship between the Nusselt and Reynolds numbers for $a=0, b=1$ and $a=1, b=1$ respectively. Along the channel with a given inward flow, the Nusselt numbers $N u\left(\eta_{1}\right)$ and $N u\left(\eta_{2}\right)$ increase along a constant $K$ line with an increase in the Reynolds number by the $N u \propto R e$ relationship; whereas at a given cross-section in the channel, the Nusselt numbers vary with the Reynolds number along a constant $\chi$ line. They approach a fairly constant value at very low values of the Reynolds number following a rapid increase with an increase in the Reynolds number. A more and more distinct difference between the two Nusselt numbers is observed as the absolute value of $a / b$ increases. Figures 13 and 14 give the relationship between the Sherwood and Reynolds numbers for the mass source of $R=1 \cdot 0$. The 


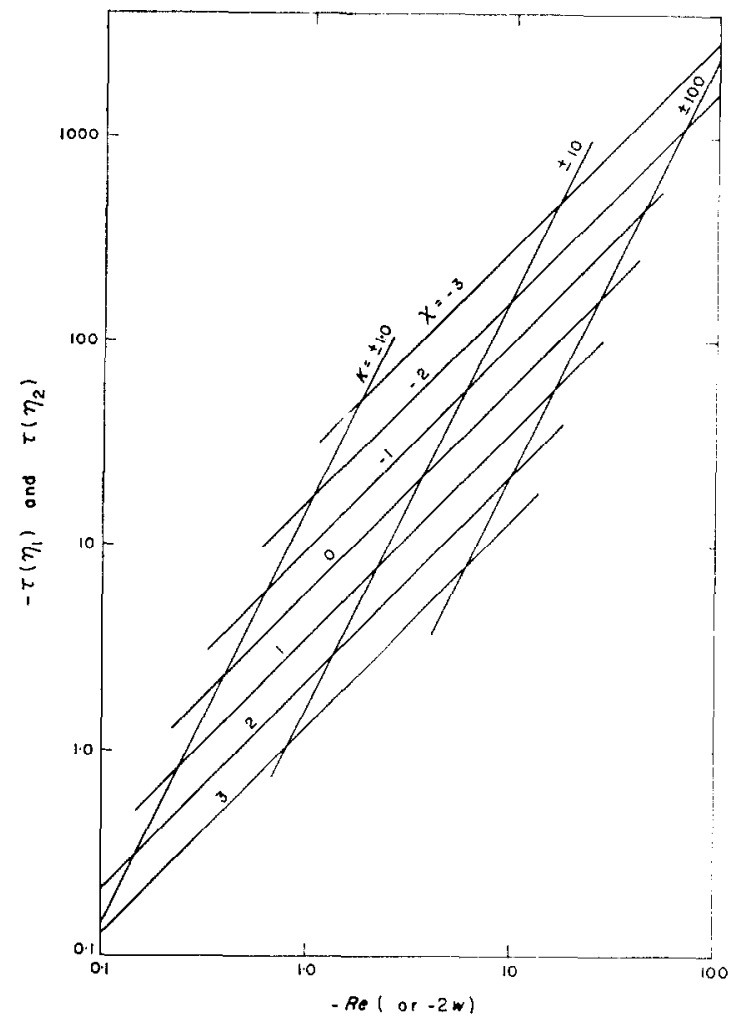

FIG. 9. $\tau$ vs $R e$ between logarithmic spiral channels $\eta_{1}=0$ and $\eta_{2}=1.0$ with $a=0$ and $b=1.0$.

Sherwood numbers $S h\left(\eta_{1}\right)$ and $S h\left(\eta_{2}\right)$ increase very rapidly along the channel wall for a given flow; whereas at a given cross-section in the channel, the Sherwood numbers approach a fairly constant value at low values of the Reynolds number following a decrease with an increase in the Reynolds number. The comparison of Figs. 13 and 14 indicates that the difference between $S h\left(\eta_{1}\right)$ and $S h\left(\eta_{2}\right)$ becomes more and more distinct as the absolute value of $a / b$ increases.

The velocity, temperature, and concentration are represented in Fig. 15 for circular Couette flow, another interesting special case. This corresponds to two concentric circular channels with $\eta_{1}=0$ and $\eta_{2}=1.0$ (or $r_{1}=0.6$ and $r_{2}=$ $1.0)$; inner one at stationary and outer one rotating with tangential velocity of unity.

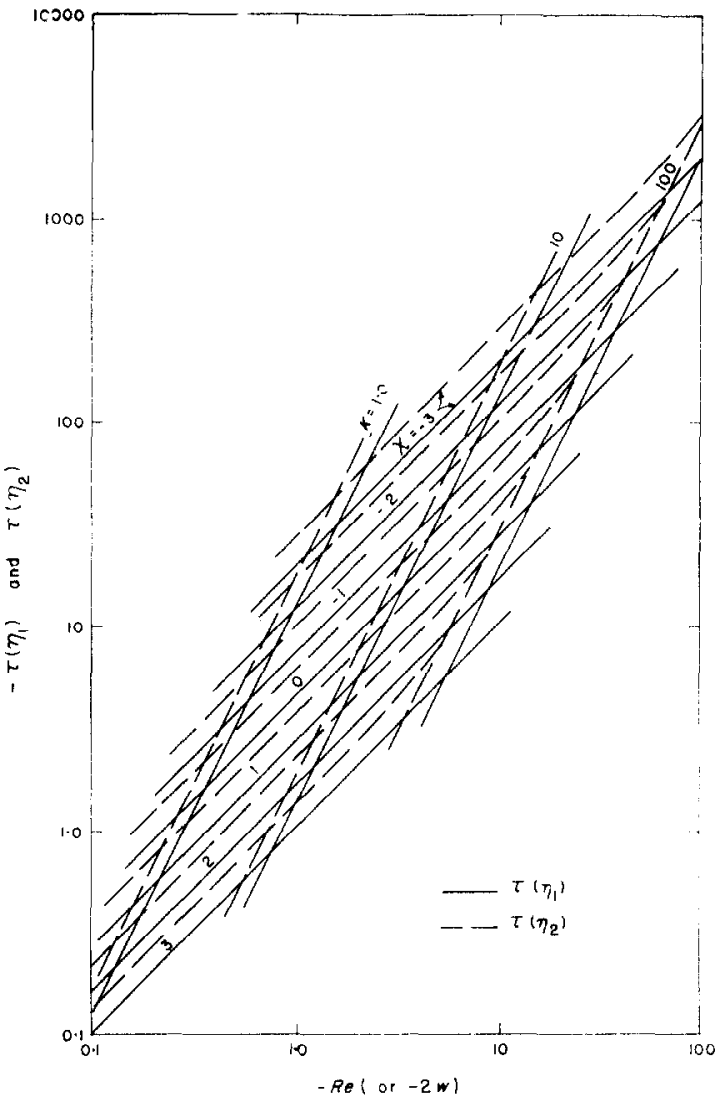

FIG. 10. $\tau$ vs $R e$ between logarithmic spiral channels $\eta_{1}=0$ and $\eta_{2}=1.0$ with $a=1.0$ and $b=1.0$.

Figure 15 shows that the maximum value of the temperature profile is shifted toward the rotating wall while that of the concentration profile toward the stationary wall, irrespective of the Prandtl number and the strength of mass source.

\section{CONCLUSIONS}

From this theoretical study, the following conclusions are reached:

1. The maxima of the velocity and temperature profiles in viscous flow shift toward the outer channel wall, whereas that of the concentration profile shifts to the inner wall. Only for the radial plane flow, all profiles have their maximum at the center of the channel.

2. For a specified fluid with a given flow, as the absolute value of $a / b$ increases, the 


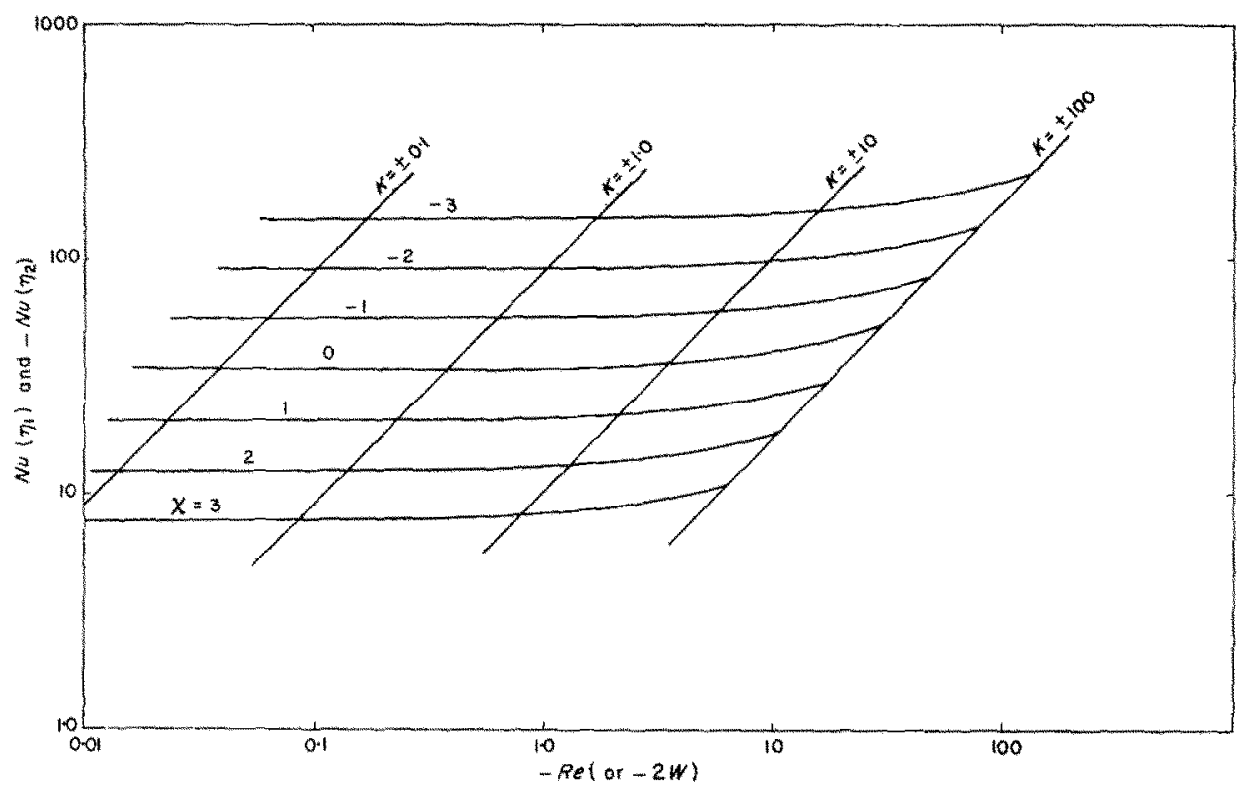

Fic. 11. $N u$ vs $R e$ for $\operatorname{Pr}=1$ between logarithmic spiral channels $\eta_{1}=0$ and $\eta_{2}=1.0$ with $a=0$ and $b=0 \cdot 1$.

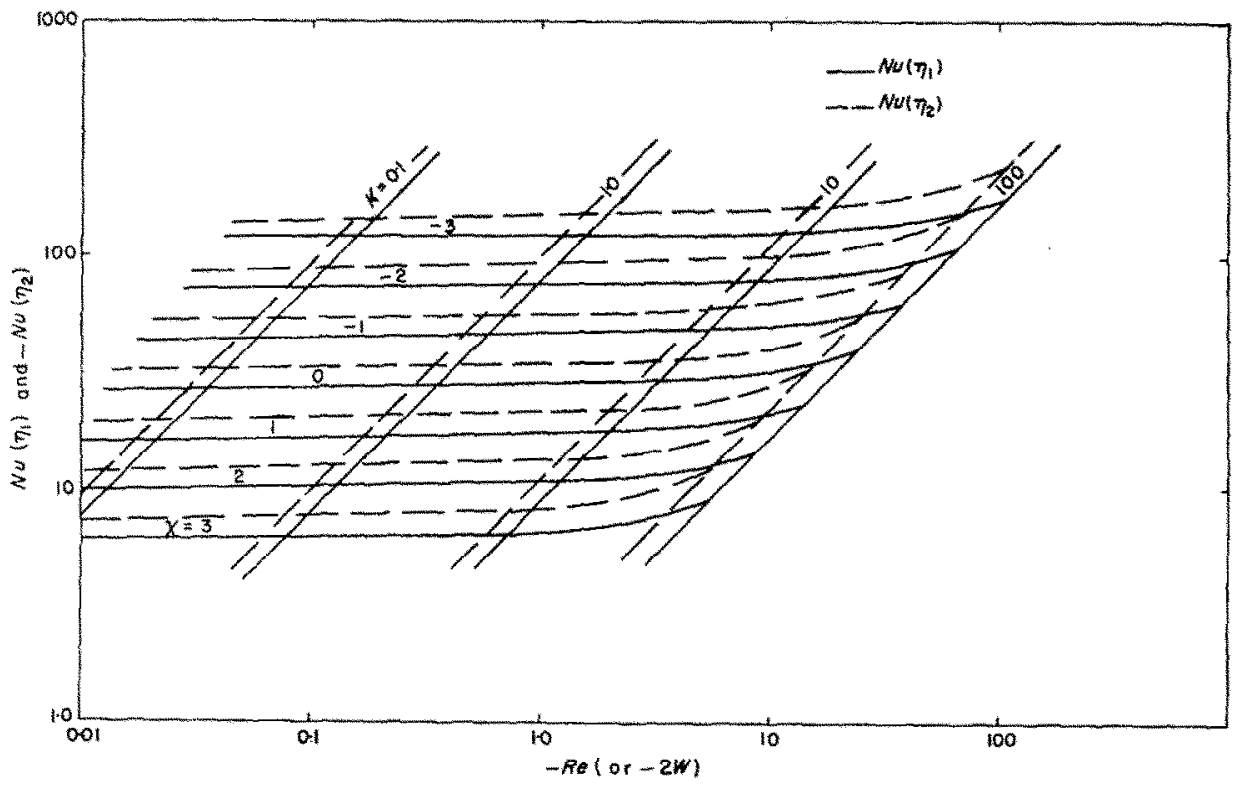

FiG. 12. $N u$ vs $\operatorname{Re}$ for $\operatorname{Pr}=1$ between logarithmic spiral channels $\eta_{1}=0$ and $\eta_{2}=1.0$ with $a=1$ and $b=1$. 


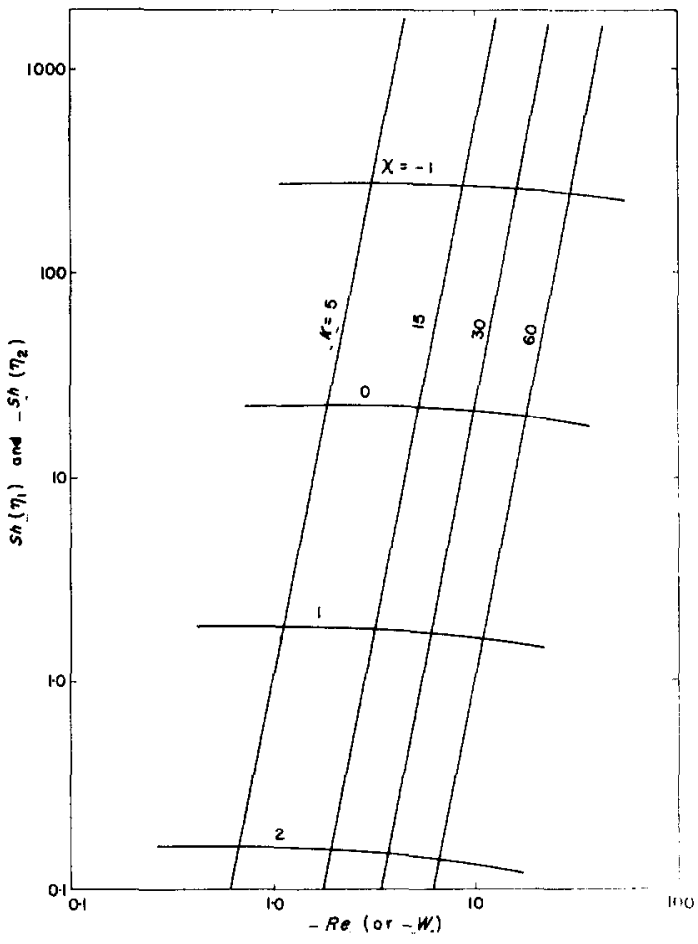

Fig. 13. $S h$ vs $R e$ for $S c=R=1.0$ between logarithmic spiral channels $\eta_{1}=0$ and $\eta_{2}=0$ with $a=0$ and $b=1 \cdot 0$.

velocity and temperature decrease in magnitude accompanied by the shift of their maxima to the outer channel wall, while concentration increases in magnitude accompanied by the shift of its maximum to the inner channel wall.

3. At low values of the Prandtl number, both the Nusselt and Sherwood numbers approach a fairly constant value. But with an increase in the Prandtl number, the former increases while the latter decreases.

4. The shear stress, Nusselt and Sherwood numbers vary with the Reynolds number in two distinct ways: Firstly, if the change in the Reynolds number is due to the change of flow rate along the channel, then the wall shear stress changes as the second power, the Nusselt number changes linearly and the Sherwood number changes as the fifth power of the Reynolds number. Secondly, if the change in the Reynolds number is

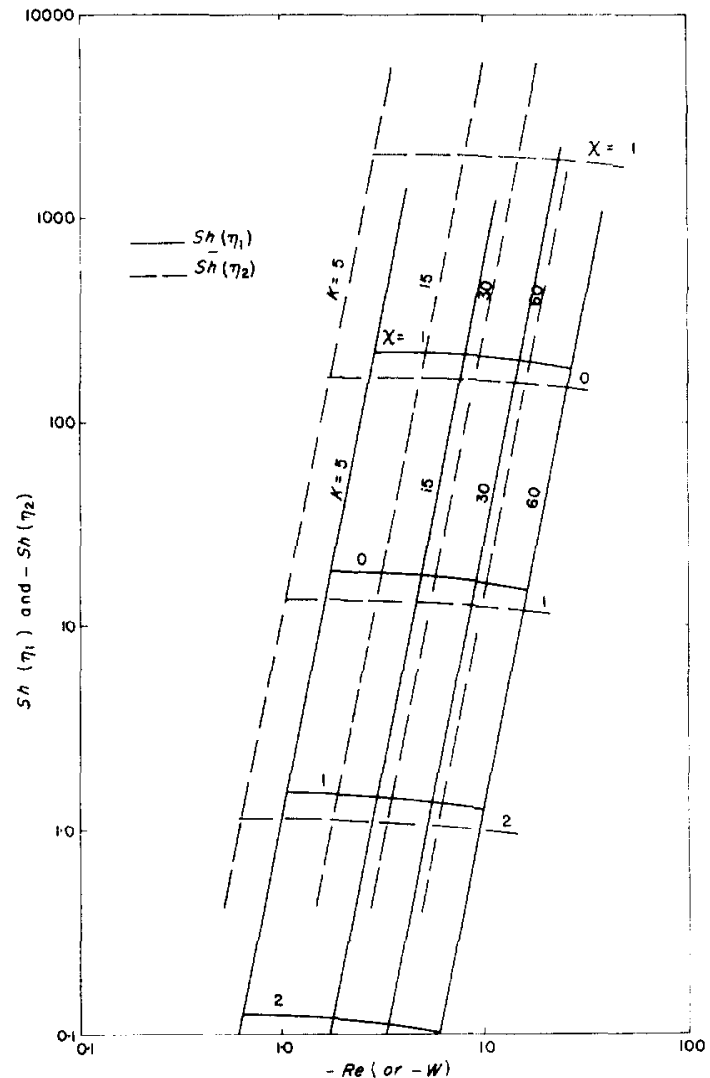

FIG. 14. $S h$ vs $R e$ for $S c=R=1.0$ between logarithmic spiral channels $\eta_{1}=0$ and $\eta_{2}=1.0$ with $a=1.0$ and $b=1 \cdot 0$.

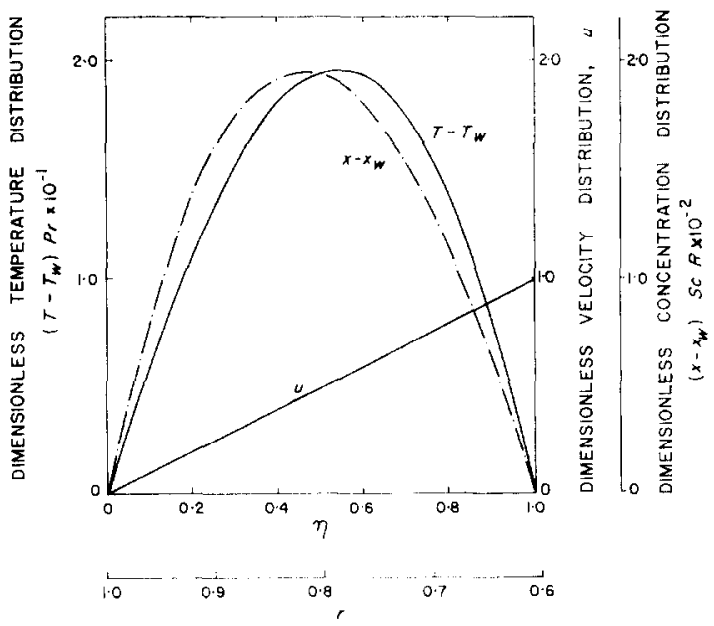

FIG. 15. Velocity, temperature and concentration distribution in circular Couette flow for $a=10$, $b=0$. 
due to the change of flow rate in the channel, then as the Reynolds number increases, the wall shear stress follows a rapid change and, the Nusselt and Sherwood numbers approach a fairly constant value at low Reynolds numbers following an increase in the former and a decrease in the latter as the Reynolds number increases.

\section{ACKNOWLEDGEMENT}

The author gratefully acknowledges the financial support of the Horace H. Rackham School of Graduate Studies and the co-operation of the Computing Center at the University in the conduct of this research. The assistance of Dr. P. S. Larsen in programming for the computer is highly appreciated.

\section{REFERENCES}

1. G. B. JEFFERY, On the steady rotation of a solid of revolution in viscous fluid, Proc. Lond. Math. Soc. 14, 327-338 (1915).
2. G. Hamel, Spiralformige Bewegungen zaher Flussigkeiten, Jahrb. Dtsch. Math. Ver. 25, 34-60 (1916).

3. C. Millikan, Logarithmic spiral flow of an incompressible fluid, Math. Ann. 101, 446-451 (1929).

4. O. Olsson and H. FAXÉn, Laminare Bewegungen zaher Flussigkeiten in logarithmischen Spiralen, Zeit. Angew. Math. Mech. 7, 496-498 (1927).

5. C. W. OseeN, Exakte Losungen der hydrodynamischen Differentialgleichungen I, Ark. Math. 20A, 24 (1927).

6. M. A. Rosenblat, Solutions exactes des équations du mouvement des liquides visqueux, $\mathrm{Mem}$. Sci. Math. 72 (1935).

7. W. J. YANG, Solutions for velocity, temperature and concentration distribution in spiral viscous flows. Unpublished Report, Heat Transfer and Thermodynamics Laboratory, Univ. of Mich. (1963).

8. W. J. YANG, General exact solutions for the diffusion equations of momentum, heat and mass in spiral viscous flows, J. Appl. Phys. 35, 1749-1751 (1964).

9. G. BIRKoFf, Hydrodynamics, Rev. Ed. University Press, Princeton (1960).

10. R. P. AGNEw, Differential Equation, 2nd Ed. McGraw-Hill, New York (1960).

Résumé-Cet article présente une recherche théorique du transport de quantité de mouvement, de chaleur et de masse dans l'écoulement visqueux incompressible à travers un canal en spirale logarithmique. Les profils de vitesse, de température et de concentration sont calculés par intégration directe des équations différentielles ordinaires obtenues à partir des équations de transport au moyen d'une technique de transformation par similitude. Des résultats numériques sont obtenus pour la contrainte de cisaillement et les vitesses de transport de chaleur et de masse aux parois du canal. On donne, comme cas spécial, la solution analytique explicite pour l'écoulement de Couette circulaire. Les résultats peuvent être appliqués à l'échangeur de chaleur à plaque spirale du type de Rosenblad et le refroidissement des paliers.

Zusammenfassung-Die Arbeit behandelt eine theoretische Untersuchung von Impuls-Energie- und Stoffaustausch in inkompressibler, zäher Strömung in einem Kanal von der Form einer logarithmischen Spirale. Geschwindigkeits-, Temperatur- und Konzentrationsprofil werden durch Integration der gewöhnlichen Differentialgleichungen errechnet, die mit Hilfe der Ähnlichkeitstransformation aus den Transportgleichungen erhalten werden. Numerische Ergebnisse wurden für Schubspannung und den Wärme- und Stoffstrom an den Kanalwänden erhalten. Als Spezialfall ist die analytische Lösung in geschlossener Form, für die kreisförmige Couette-Strömung angegeben. Die Ergebnisse lassen sich auf den dampfbeheizten Rosenblad Spiralplatten-Wärmeübertrager und die Kühlung von Lagern anwenden.

Аннотация-Статья посвещена теоретическому исследованию переноса количества движения, тепла и вещества при течении несжимаемой вязкой жицкости через канал в виде логарифмической спирали. Рассчитаны профили скорости, температуры и концентрации путем непосредственного интегрирования обыкновенных дифференциальных уравнений, полученных преобразованиями полобия исходных уравнений переноса. Получены численные результаты для напряжения сдвига, а также потоков тепла и вещества на стенках канала. Как частный случай приводитсн аналитическое решение в замкнутой форме для кругового куәттовского течения. Полученные результаты можно применить к расчетам охлаждения подшипников и работающих на пару спиральных пластинчатых теплообменников типа Розенблада. 